\title{
A interdisciplinaridade em um curso de extensão como forma de empoderamento feminino na computação
}

\author{
Sara L. de Farias ${ }^{1}$, Maria Isabela S. Nunes ${ }^{1}$, Thalia S. de Santana ${ }^{1}$, Natália do C. \\ Louzada $^{1}$, Ramayane B. Braga ${ }^{1}$, Adriano H. Braga ${ }^{1}$ \\ ${ }^{1}$ Instituto Federal Goiano - Campus Ceres (IF GOIANO) \\ Caixa Postal 51 - 76.300-000 - Ceres - GO - Brasil \\ \{sara.farias,maria.isabela\}@estudante.ifgoiano.edu.br, \\ \{thalia.santana, natalia.louzada, ramayane.santos, \\ adriano.braga\}@ifgoiano.edu.br
}

\begin{abstract}
During the year 2020, due to the pandemic caused by COVID-19, an entirely online course was offered with free registration for any participants. The course's programmatic content covered mainly the following themes: Introduction to Feminist Studies, History of Women in Computing and Computational Thinking, totaling a workload of 100 hours. The initiative reached participants from 17 Brazilian states, who evaluated it as socially important, especially for its interdisciplinary approach to content is often not addressed in regular courses.
\end{abstract}

Resumo. Durante o ano de 2020 em decorrência da pandemia provocada pela COVID-19 foi ofertado um curso totalmente online com inscrição gratuita e livre para quaisquer participantes. $O$ conteúdo programático do curso abordou principalmente os seguintes temas: Introdução aos Estudos Feministas, História das Mulheres na Computação e Pensamento Computacional, totalizando uma carga horária de 100 horas. A iniciativa alcançou participantes de 17 estados brasileiros, os quais avaliaram-na como socialmente importante, em especial, por abordar interdisciplinarmente conteúdos que frequentemente não são contemplados em cursos regulares.

\section{Introdução}

O projeto Meninas Digitais no Cerrado surgiu no ano de 2016 com o desejo de despertar entre estudantes do nível médio o interesse em seguir carreiras no campo da Computação. Diante de um cenário em que menos de $14 \%$ dos integrantes dos cursos superiores da referida área são mulheres [SBC 2021], desde o princípio, a iniciativa visou apresentar a História da Computação sob a perspectiva do protagonismo feminino, superando a invisibilização feminina no âmbito da história desta ciência. Esta abordagem foi oferecida por meio de palestras, oficinas itinerantes, debates e workshops, como forma de incentivo e identificação com a área.

Em decorrência da COVID-19, a rotina da sociedade mudou, sendo necessário adaptar ações inicialmente idealizadas como presenciais para o ambiente virtual. Após o êxito do projeto no desenvolvimento de algumas atividades online, as quais obtiveram alcance nacional facilitando a disseminação do conhecimento, foi possível elaborar e promover um curso de extensão integralmente online. Com inscrições gratuitas e livres, 
buscou-se trabalhar o empoderamento feminino por intermédio da História das Mulheres na Computação, periodizada a partir das diferentes gerações de computadores.

Destacamos que há como ensinar a História das Mulheres na Computação por meio de atividades diversificadas. Considerando os anais do Women in Information Technology (WIT), desde 2016 são relatadas várias iniciativas que vêm se debruçando sobre esta narrativa em panorama feminino, utilizando desde jogos de cartas [Figueiredo e Santos 2016] até oficinas de lixo eletrônico [Cruz et al. 2020]. Nesse contexto, o presente trabalho relata a ação de um curso pioneiro acerca do recorte do gênero das Mulheres na Computação. Este curso resulta de uma sequência de ações anteriores, ao longo de cinco anos de execução de um projeto de extensão atuante na temática.

\section{Relato de Experiência}

No ano de 2020, no âmbito da execução do projeto de extensão, foi ofertada a primeira edição de um curso na modalidade à distância, via plataforma Moodle, totalizando uma carga horária de 100 horas, dividida em três módulos distintos. A equipe foi composta por quatro docentes e duas discentes de nível médio técnico.

O material didático foi elaborado com base em diversas obras, websites e artigos, os quais compuseram o referencial teórico do curso, indo desde acontecimentos históricos da computação - embasados principalmente por Wazlawick (2016) - às questões de gênero e fundamentos de informática e também pensamento computacional.

A fim de alcançar amplamente a comunidade interessada, o curso foi divulgado no mês de setembro de 2020 por meio das redes sociais e aplicativos de comunicação instantânea, tais como: Facebook, Instagram e WhatsApp, além de listas de e-mails relacionadas a projetos de mulheres na computação com alcance nacional. Houve 149 inscrições de 17 estados de norte a sul do país, destas, 139 discentes do gênero feminino com faixa etária variando entre 14 e 57 anos, tendo idade média de 23 anos.

O acompanhamento dos estudantes foi realizado no ambiente virtual de aprendizagem (AVA) Moodle, bem como por meio de interações em um grupo no aplicativo de mensagens WhatsApp, criado exclusivamente para que fosse possível uma comunicação mais dinâmica e próxima aos cursistas. A seleção da plataforma AVA se deu pelo vasto número de recursos providos, tais como fóruns, tarefas, questionários, além de estatísticas e logs de acesso dos estudantes matriculados.

Desta forma, as aulas se iniciaram no mês de outubro, estendendo-se até meados de dezembro, tendo sido realizada uma aula inaugural no dia 30 de outubro, contando com a presença de 27 participantes de forma síncrona. Cada um dos módulos elaborados foram descritos no Projeto Pedagógico de Curso (PPC) - como pode ser verificado no Quadro 1 com o detalhamento da carga horária e ementa - e versaram tanto sobre temáticas consideradas pertinentes pelas(os) pesquisadoras(es) envolvidas(os), quanto por assuntos cujo interesse havia sido apontado pelo público alvo durante atividades presenciais anteriores.

Quanto aos critérios de avaliação de aprendizagem adotados, no módulo "Introdução aos estudos feministas" foi utilizado o recurso glossário colaborativo, em que cada participante redigiu um verbete distinto relativo a um conceito da teoria feminista, ou a uma personagem histórica do movimento social feminista. 
Quadro 1. Definição dos módulos ofertados no curso. Fonte: Própria (2021).

\begin{tabular}{|c|c|c|}
\hline Módulos & Carga Horária & Ementa Básica \\
\hline $\begin{array}{c}\text { Módulo I: Introdução } \\
\text { aos Estudos } \\
\text { Feministas }\end{array}$ & $20 \mathrm{~h}$ & $\begin{array}{c}\text { A construção de um Ocidente patriarcal; O movimento } \\
\text { feminista pela conquista de direitos; A história dos direitos } \\
\text { das mulheres no Brasil; Violência e vulnerabilidade } \\
\text { feminina; Questões de gênero e sexualidade. }\end{array}$ \\
\hline $\begin{array}{c}\text { Módulo II: } \\
\text { História das } \\
\text { Culheres na }\end{array}$ & $60 \mathrm{~h}$ & $\begin{array}{c}\text { Geração e } 5^{\mathrm{a}} \text { Geração de Computadores; Reconstruçãa da } \\
\text { história da computação sob a perspectiva de todes. }\end{array}$ \\
\hline $\begin{array}{c}\text { Módulo III: } \\
\text { Pensamento } \\
\text { Computacional }\end{array}$ & $20 \mathrm{~h}$ & $\begin{array}{c}\text { Conceito de pensamento computacional (PC); Pilares de } \\
\text { PC; Computação desplugada; Introdução à lógica e } \\
\text { programação de computadores. }\end{array}$ \\
\hline
\end{tabular}

Já no segundo módulo, intitulado "História das mulheres na computação", o qual compreendeu a maior carga horária (60h), contribuições e personagens femininas na área de computação foram apresentadas de forma bem enfática, separadas por cada uma das gerações de computadores. Os discentes foram avaliados de duas formas (Figura 1): um storyboard (imagem digital sucinta elaborada contendo uma imagem e sua descrição) com a seleção de quatro mulheres da computação e sua principal realização, e um mapa mental, para visualização da contribuição feminina na computação: datas, máquinas de destaque e protagonistas mulheres que permearam a história da computação até os dias mais atuais.
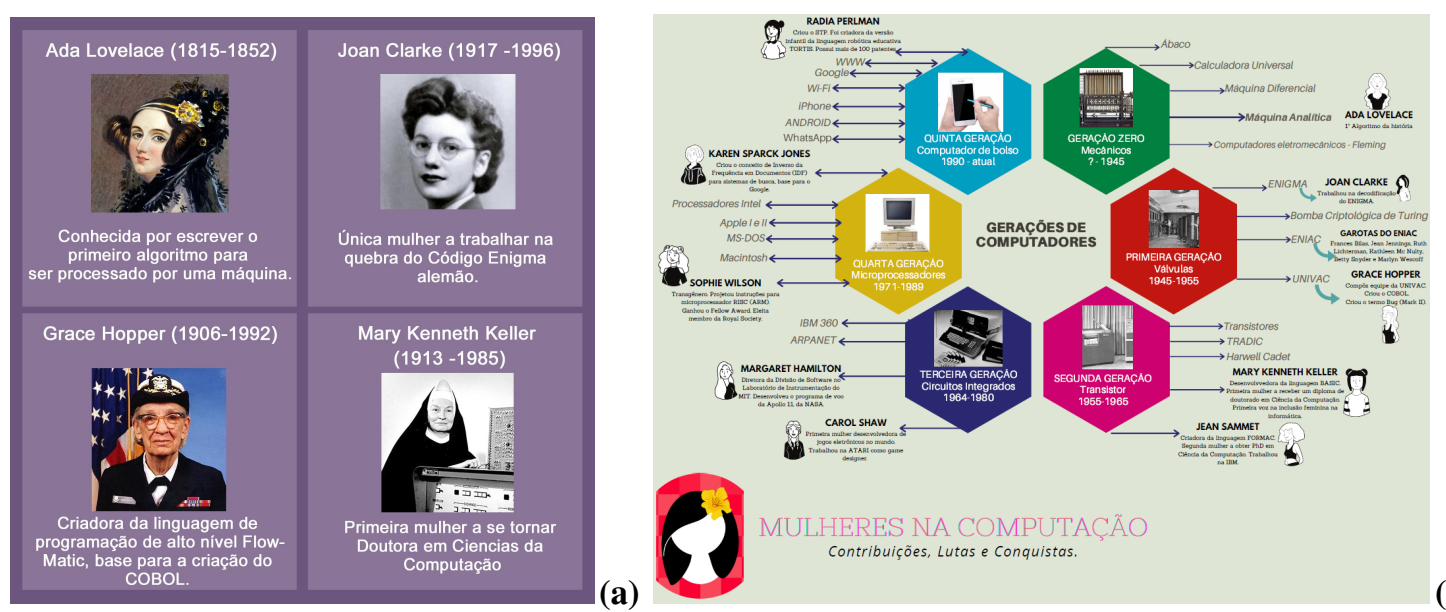

(b)

Figura 1. Atividades entregues: a) storyboard, b) mapa mental. Fonte: Própria (2020).

Por fim, o módulo "Pensamento Computacional" desafiou os discentes a produzirem um jogo ou história animada com base nos conteúdos aprendidos nos módulos passados, a exemplo de quizzes sobre os conceitos de gênero ou mesmo, animações recontando a vida de mulheres tais como Ada Lovelace. Conectando assim os conteúdos dispostos na ementa de maneira interdisciplinar, a propósito de conquistar integração entre conceitos importantes para uma formação tanto humanista quanto básica em informática. Ao final, os participantes só foram considerados aptos à certificação desde que tivessem aproveitamento mínimo de 50\% (aprovação) no curso. 
Para alcançar os objetivos descritos anteriormente, algumas ferramentas foram introduzidas a fim de propiciar a capacitação tecnológica como instrumento mediador do aprendizado. A exemplo disso, no Módulo 2 foi inserida a ferramenta Canva ${ }^{1}$, uma plataforma que possibilita criações de designs, incluso mapas mentais como artes digitais. Por conseguinte, no Módulo 3 os estudantes fizeram uso do $\mathrm{Scratch}^{2}$, uma plataforma de ensino de lógica de programação por intermédio de blocos interativos. $\mathrm{O}$ emprego destas ferramentas foi de suma importância para que os discentes conhecessem e se apropriassem de novas possibilidades técnicas para a expressão criativa.

Ademais, apesar do curso ter sido realizado na modalidade à distância, em que é privilegiada a assincronicidade no acesso, a fim sanar possíveis dúvidas e discutir os conteúdos abordados, as tutoras e os respectivos professores realizaram três encontros em tempo real pelo ambiente Google Meet, os quais estiveram focados na revisão de cada um dos módulos ofertados antes da entrega final das avaliações.

\section{Resultados e Discussão}

O curso foi considerado satisfatório pela avaliação dos estudantes ao final do mesmo. Cerca de 50 discentes responderam voluntariamente um questionário sobre a experiência que obtiveram com o curso. Destes, $80 \%$ conseguiram entregar todas as atividades propostas, atribuindo um nível de dificuldade de escala entre 1 a 5 (sendo 1 pouca dificuldade e 5, maior dificuldade), onde boa parte dos cursistas (60\%) afirmaram possuir nível 3 de dificuldade. Ao todo, 38 estudantes foram certificados, sendo este número considerado alto em decorrência aos diversos fatores externos direta e indiretamente relacionados às dificuldades sociais e de saúde pública impostas às pessoas no contexto.

Acerca das atividades propostas, verificou-se que houve um bom aprendizado e aproveitamento do curso desenvolvido. De acordo com os dados coletados, $92 \%$ dos estudantes ficaram extremamente satisfeitos ou satisfeitos com o aprendizado adquirido após a finalização. Sobre aspectos do curso, em relação ao conteúdo abordado, relevância das informações, metodologia utilizada e tutoria, todos os itens superaram as expectativas dos inscritos. Já em relação ao ambiente virtual de aprendizagem e carga horária proposta, os participantes informaram atender as expectativas dos mesmos.

A Figura 2 apresenta os principais pontos positivos citados pelos discentes:

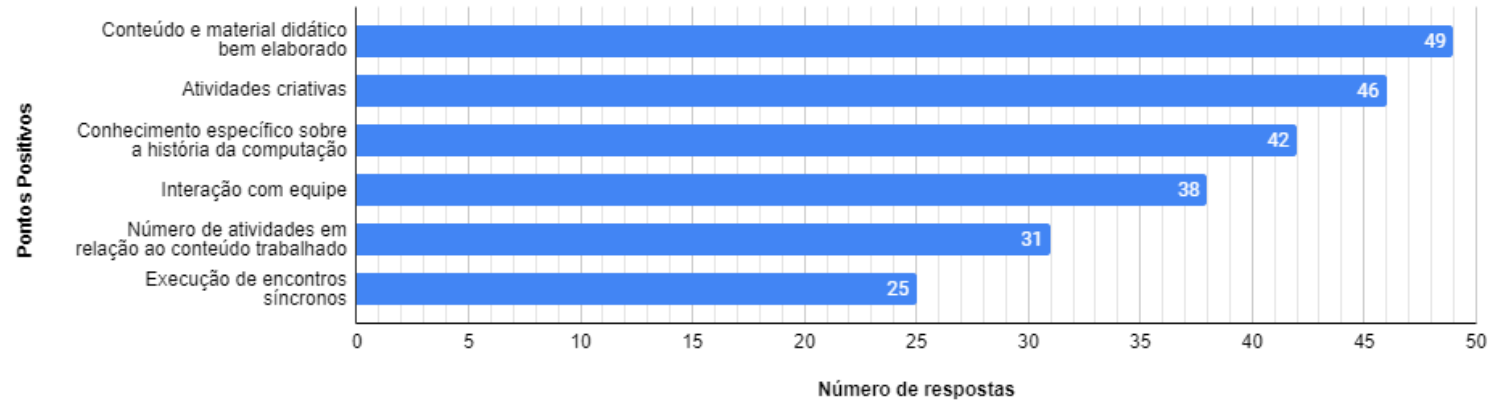

Figura 2. Avaliação dos fatores de maior impacto no curso. Fonte: Própria (2021).

\footnotetext{
${ }^{1}$ https://www.canva.com/

${ }^{2}$ https://scratch.mit.edu/
} 
No formulário foi inserido um questionamento subjetivo para que os participantes pudessem deixar algum comentário, sugestão ou dúvida. As considerações deixadas por eles foram significativas, como por exemplo: "Foi muito bom o curso. Continuem com esse importantíssimo trabalho.". Houve ainda críticas construtivas, para melhorias em edições futuras, como "O curso foi excelente. Superou minhas expectativas. Minha única sugestão é estender a carga horária do módulo Pensamento Computacional." Todos os respondentes participariam novamente de ações realizadas pelo projeto em questão, além de afirmarem recomendar a amigos, colegas e familiares.

\section{Considerações Finais}

Tendo em vista o diferencial do curso de extensão apresentado, foi possível integrar três temáticas conjuntas ainda não abordadas anteriormente de forma interdisciplinar. Os estudantes puderam apresentar ao final um projeto integrador, contando uma história feminista da computação e trazendo assim, resultados satistórios correlacionando os conhecimentos obtidos. Além disso, por meio de uma realização integralmente virtual propiciou-se maior alcance ao projeto, dado que 55,7\% dos inscritos não o conheciam anteriormente, e aproximadamente 54,4\% não eram do estado do mesmo.

Desta maneira, espera-se que esta iniciativa colabore na promoção da diversidade de gênero no âmbito área de computação, compondo uma estratégia exitosa para a desconstrução, desnaturalização de estereótipos e discriminações relativas às mulheres no campo da informática, podendo inclusive inspirar demais projetos parceiros do Programa Meninas Digitais da Sociedade Brasileira de Computação (SBC), principalmente no que tange ao estímulo e empoderamento feminino na computação.

Em trabalhos futuros, espera-se ampliar o quantitativo de estudantes atendidos por meio da oferta de novas turmas. Outrossim, alguns esforços atuais já estão sendo promovidos, haja vista que a instituição de ensino ligada ao projeto se propôs a incentivar de forma institucional o curso em questão por meio de bolsas às estudantes, possibilitando assim a realização de mais uma edição da atividade pelo projeto Meninas Digitais no Cerrado contemplando novos públicos-alvos.

\section{Referências}

Cruz, M., Bim, S., Battezzati, L., Santos, M., Berardi, R., \& Paiva, V. (2020). Criação de representações usando e-lixo para homenagear mulheres da Computação. In Anais do XIV Women in Information Technology, (pp. 199-203). Porto Alegre: SBC. doi:10.5753/wit.2020.11294

Figueiredo, K., \& Santos, J. (2016). Computasseia: destacando a participação feminina na História da Computação. In Anais do X Women in Information Technology, (pp. 16-19). Porto Alegre: SBC. doi:10.5753/wit.2016.9692

SBC (2021). Educação Superior em Computação - Estatísticas 2019. Disponível em: $<$ https://www.sbc.org.br/documentos-da-sbc/send/133-estatisticas/1324-educacao-su perior-em-computacao-estatisticas-2019>.

Wazlawick, R. S. (2016). História da computação. Rio de Janeiro: Elsevier Brasil. 